FILE COPY

NBSIR 77-857

DO NOT REMOVE

\title{
CRYOGENIC DESIGN AND SAFETY REVIEW NASA-LANGLEY RESEARCH CENTER O.3 METER TRANSONIC CRYOGENIC TUNNEL
}

R. O. Voth

T.R. Strobridge

Cryogenics Division

Institute for Basic Standards

National Bureau of Standards

Boulder, Colorado 80302

April 1977

Prepared for:

Dr. Robert A. Kilgore

National Aeronautics and Space Administration

Langley Research Center

Hampton, Virginia 23665 



\section{NBSIR 77-857}

\section{CRYOGENIC DESIGN AND SAFETY REVIEW NASA-LANGLEY RESEARCH CENTER O.3 METER TRANSONIC CRYOGENIC TUNNEL}

R. O. Voth

T.R. Strobridge

Cryogenics Division

Institute for Basic Standards

National Bureau of Standards

Boulder, Colorado 80302

April 1977

Prepared for:

Dr. Robert A. Kilgore

National Aeronautics and Space Administration

Langley Research Center

Hampton, Virginia 23665

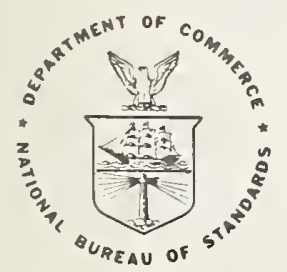

U.S. DEPARTMENT OF COMMERCE, Juanita M. Kreps, Secretary Sidney Harman, Under Secretary

Dr.-Betsy Ancker-Johnson, Assistant Secretary for Science and Technology

NATIONAL BUREAU OF STANDARDS, Ernest Ambler, Acting Director 
1.0 INTRODUCTION . . . . . . . . . . . . . . . I

2.0 COMPONENT REVIEW ........................ 2

2.1. Storage Tank Fill Transfer Line . . . . . . . . . . 2

2.2. Liquid Nitrogen Storage Tanks.............. 2

2.2.1. Vacuum space relief valves .......... 2

2.2.2. Storage tank schematic drawing ......... 2

2.2.3. Vacuum leak - tank A. . . . . . . . . . 4

2.3. Liquid Nitrogen Transfer System to the Tunnel . . . . . . 4 4

2.3.1. Replumbing of liquid return line ........ 4

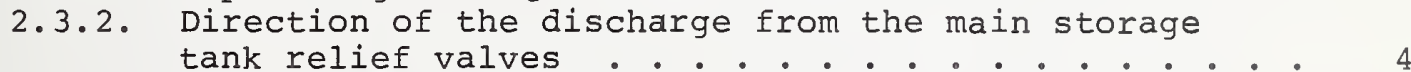

2.3.3. Protective clothing for use in the nitrogen .... 6

2.4. Tunnel structure ............... . . 6

2.5. Tunnel Insulation . . . . . . . . . . . . . 6

2.6. Tunnel Vent Piping and Pressure Relief .......... 7

2.6.1. Cryogenic valve stem position ......... 7

2.6.2. Carbon liquid sensor ........... . 7

2.7. Controls and Instrumentation ........... 13

2.7.1. Remote storage tank liquid level and pressure gauges. 13

2.7.2. House air supply - receiver ........... 13

2.7.3. Digital valves ............. 13

2.7.4. Control system for tunnel pressure and temperature. 13

2.8. Safety Systems . . . . . . . . . . . . 14

2.8.1. Oxygen analysis ................. 14

2.8.2. Fire control equipment .......... 14

2.9. Physical Plant Site............. . 14

3.0 SUMMARY OF RECOMMENDATIONS AND SUGGESTIONS . . . . . . . 16

4.0 REFERENCES . . . . . . . . . . . . . . 17

APPENDIX A. COST OF BOILOFF LIQUID NITROGEN AS A FUNCTION OF

INSULATION SPACE PRESSURE ............... 18

APPENDIX B. ESTIMATED COST OF RECOVERING NITROGEN GAS AND

REFRIGERATION FROM THE $0.3 \mathrm{~m}$ TRANSONIC CRYOGENIC

TUNNEL VENT 


\section{.}




\title{
CRYOGENIC DESIGN AND SAFETY REVIEW
}

\section{NASA-LANGLEY RESEARCH CENTER 0.3 METER TRANSONIC CRYOGENIC TUNNEL}

\author{
R. O. Voth and T. R. Strobridge \\ Cryogenics Division \\ Institute for Basic Standards \\ National Bureau of Standards \\ Boulder, Colorado 80302
}

The findings of a Cryogenic Design and Safety Review of the NASA-Langley $0.3 \mathrm{~m}$ Transonic Cryogenic Tunnel are presented in this report. The tunnel working fluid and coolant is nitrogen. The nitrogen, supplied as liquid, is exhausted as a low temperature gas. The use and storage of liquid nitrogen at the facility presents several potential hazards to personnel and equipment. An appropriate cryogenic design minimizes these risks, and provides for convenient tunnel operation and for the economical use of the liquid nitrogen. The tunnel and ancilliary systems are generally well designed but several recommendations to improve the cryogenic systems are made. The cost of recovering the cold vent gas is compared to the cost of producing the required liquid nitrogen using a captive air separation plant. Although the economic analysis is preliminary, it shows that because of the periodic operation of the tunnel, a captive air separation plant has a lower annual operating cost than the vent gas recovery systems considered.

Key words: Cryogenic; design; nitrogen; safety; wind-tunnel.

\subsection{INTRODUCTION}

The Cryogenics Division of the National Bureau of Standards has completed a Cryogenic Design and Safety Review of the NASA-Langley $0.3 \mathrm{~m}$ Transonic Cryogenic Tunnel. The tunnel is operated at temperatures as low as $80 \mathrm{~K}$ and pressures as high as 5 atmospheres absolute. The working fluid and coolant is nitrogen supplied to the tunnel as liquid and exhausted as low temperature gas. Typically the use and storage of liquid nitrogen presents the following potential hazards to personnel and equipment:

1) Freezing human tissue,

2) Asphyxiation due to oxygen displacement,

3) Failure of materials not suitable for low temperature service,

4) Overpressure failures caused by trapped liquid,

5) Failure of structures due to thermal contraction,

6) Fire in flammable materials compounded by oxygen enrichment of liquid air, and

7) Fogging or icing of the adjacent area.

With regard to the above potential hazards, we find the tunnel and ancillary systems generally well designed for low temperature service and the risks eliminated or reduced to acceptable levels. Recommendations to further reduce risks or improve operation are made in subsequent sections of this report. At the time of our inspection, september 27 and 28, 1976, the tunnel had accumulated some 600 hours of operation without an accident or injury.

Since the $0.3 \mathrm{~m}$ Transonic Cryogenic Tunnel uses significant quantities of liquid nitrogen, a vent gas recovery system may be more economical than purchasing the liquid. A preliminary economic analysis of several recovery systems is presented in Appendix B. The recovery systems considered had an 
equal or higher annual cost than a captive air separation plant and nitrogen liquefier that ran continuously. The periodic vent flow and the low availability of the vent gas were the principle reasons the recovery systems were more costly.

\subsection{COMPONENT REVIEW}

Technical documents and drawings supplied by the facility staff were studied and a two day inspection was augmented by helpful discussions with the staff scientists, engineers and technicians. The tunnel was partially disassembled during the inspection. The elements reviewed and studied were storage tanks, tunnel structure, tunnel insulation, vent valves and piping, controls and instruments, safety systems, the physical plant site, and the liquid nitrogen transfer systems both from the truck loading station to the storage tanks and from the storage tanks to the tunnel.

\subsection{Storage Tank Fill Transfer Line}

Liquid nitrogen is delivered in semi-trailer tankers. The truck does not enter the site proper but fills the storage tanks through an insulated transfer line penetrating a cement block structure partially surrounding the storage tanks on two sides. The transfer line, figure 1, extends almost to the street and is firmly anchored to a stanchion. Following a horizontal run to the storage tanks, there is a right angle bend to a vertical section connecting to the larger diameter storage tank liquid manifold. Although expansion loops and bends provide stress relief for the liquid manifold, the smaller liquid fill line is restrained at both ends. Estimating a $7.6 \mathrm{~m}$ transfer line length, the calculated free thermal contraction is $2.3 \mathrm{~cm}$; if the line were fixed firmly at both ends, the stress would be above yield.

Even though the line has been in service for some time, we recommend that calculations be made, considering the restraints and contraction of the storage tank liquid manifold, to determine the stress in the fill transfer line. If these stresses are not acceptable, then design changes should be made and the piping modified. Note that the forces imposed by making and breaking the truck connection should not be reacted by the transfer line.

\subsection{Liquid Nitrogen Storage Tanks}

Liquid nitrogen is stored in two conventionally designed, evacuatedpowder insulated 28,000 gallon tanks. A pressure building vaporizer and the liquid nitrogen pump to supply the tunnel are located in the storage tank area.

\subsubsection{Vacuum space relief valves}

The storage tanks schematic drawing shows a relief device for the evacuated insulation space. There were no relief devices on the vacuum space at the time of our inspection.

We recommend that appropriate relief valves be installed.

\subsubsection{Storage tank schematic drawing}

We recommend that easily read schematic drawings or drawing of the storage tanks and manifolding be prepared that show at least:

1) Tank internals,

2) All penetrations and their schematic positions,

3) All piping,

4) All valves and their numbers,

5) All safety devices,

6) The pump and pressure building vaporizer, 


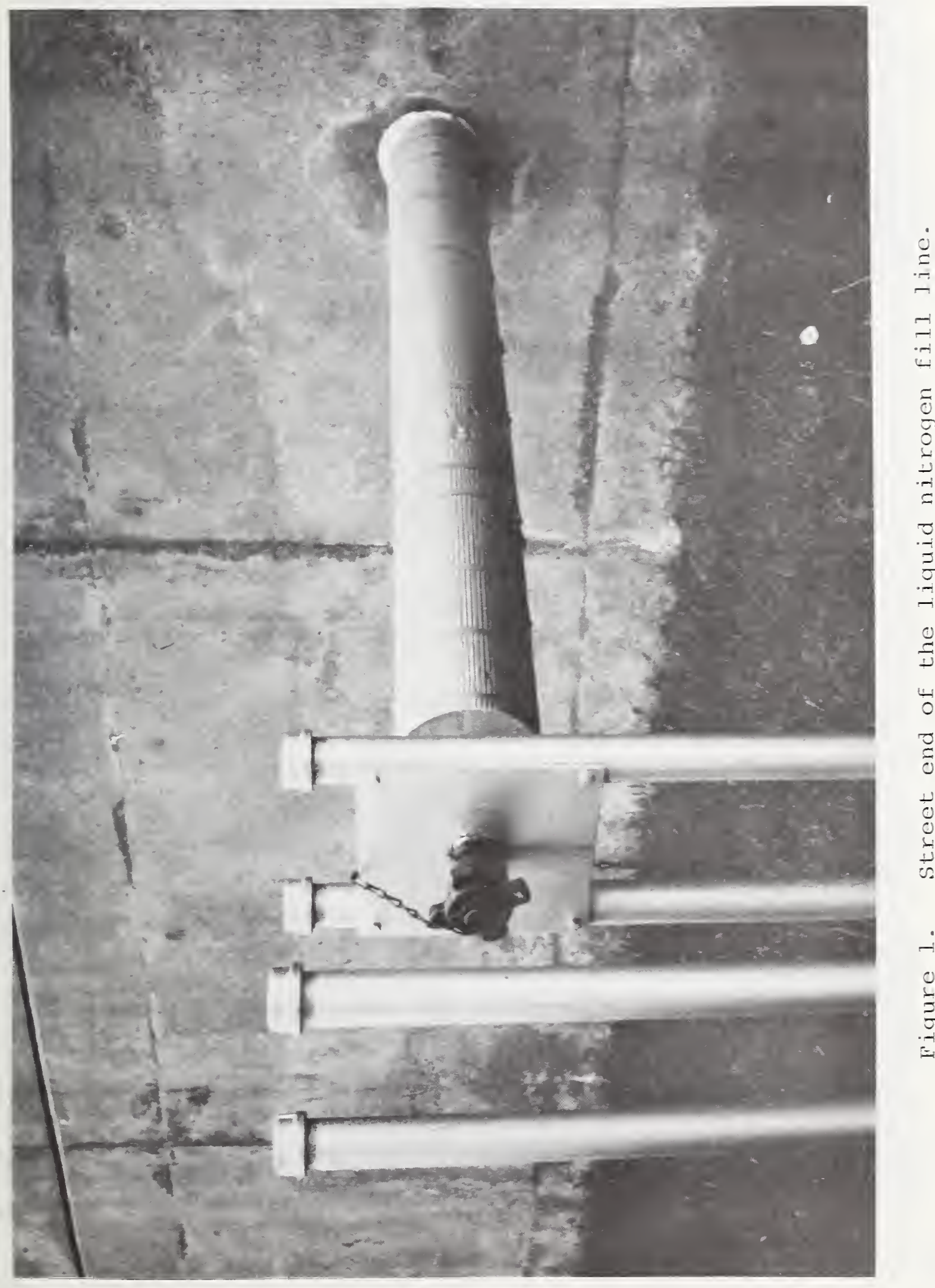


7) All transfer lines, and

8) Instruments.

Such drawings will be valuable in training new facility personnel and truck drivers or for reference by those who only occasionally operate the system.

\subsubsection{Vacuum leak - tank A}

We understand that the best vacuum ever attained in the A tank insulation space was $9.2 \times 10^{-3} \mathrm{~atm}(7 \mathrm{mmHg})$. The pressure was $0.132 \mathrm{~atm}$ (100 $\left.\mathrm{mmHg}\right) \mathrm{at}$ the time of our irspection and the vessel was being pumped. The insulation performance at $0.132 \mathrm{~atm}(100 \mathrm{mmHg})$ is essentially the same as if the space were at atmospheric pressure. In addition to being costly, see Appendix $A$, certain combinations of the leak location, operating sequence, and lack of vacuum relief could lead to collapsing the inner vessel.

We recommend that all steps necessary be taken to repair the leak and return the insulation to serviceable condition.

\subsection{Liquid Nitrogen Transfer system to the Tunnel}

The liquid nitrogen transfer lines are all foam insulated and covered with a conventional vapor barrier. Nitrogen is pumped from the storage tanks to the tunnel; excess liquid not used in the tunnel is returned to the storage tanks. Sufficient plumbing is provided so each storage tank can be used or filled independently; however, the returning excess liquid lines connect into the storage tank vent lines inboard of the vent valves. Thus, if a tank vents while flow is being returned to it, the returning liquid is forced out the tank vent. The tunnel is operated using both storage tanks to reduce the amount of liquid vented. The liquid is withdrawn from one tank while the excess liquid is returned to the other tank that is initially at low pressure.

We feel that the liquid nitrogen transfer system is adequately protected from overpressure failures due to trapped liquid and excluding the liquid fill line, the system is adequately protected from excess stress due to thermal contraction. Relief valves are present for each section of pipe that can be isolated and pipe loops are used to relieve the thermal stresses in the longer runs of piping. Because the plumbing system is located outdoors and the probability of a pipe rupture is remote, the danger of oxygen depletion in the storage area is remote.

\subsubsection{Replumbing of liquid return line}

The operational complexity resulting from the excess liquid returning to the storage tank inboard of the tank vent valves could be reduced by directing the return flow to the now unused ullage connection shown in figure 2.

We recommend this change be made to allow completely independent operation of the two tanks and to eliminate the venting of liquid nitrogen.

\subsubsection{Direction of the discharge from the main storage tank relief valves}

The discharge from the main relief valves for the storage tanks is currently located so that liquid could impinge on the carbon steel outer shell of the adjacent tanks. A liquid discharge is possible with the current liquid return plumbing or by overfilling.

We recommend directing the vent valve discharge so that liquid cannot contact the adjacent tanks. 


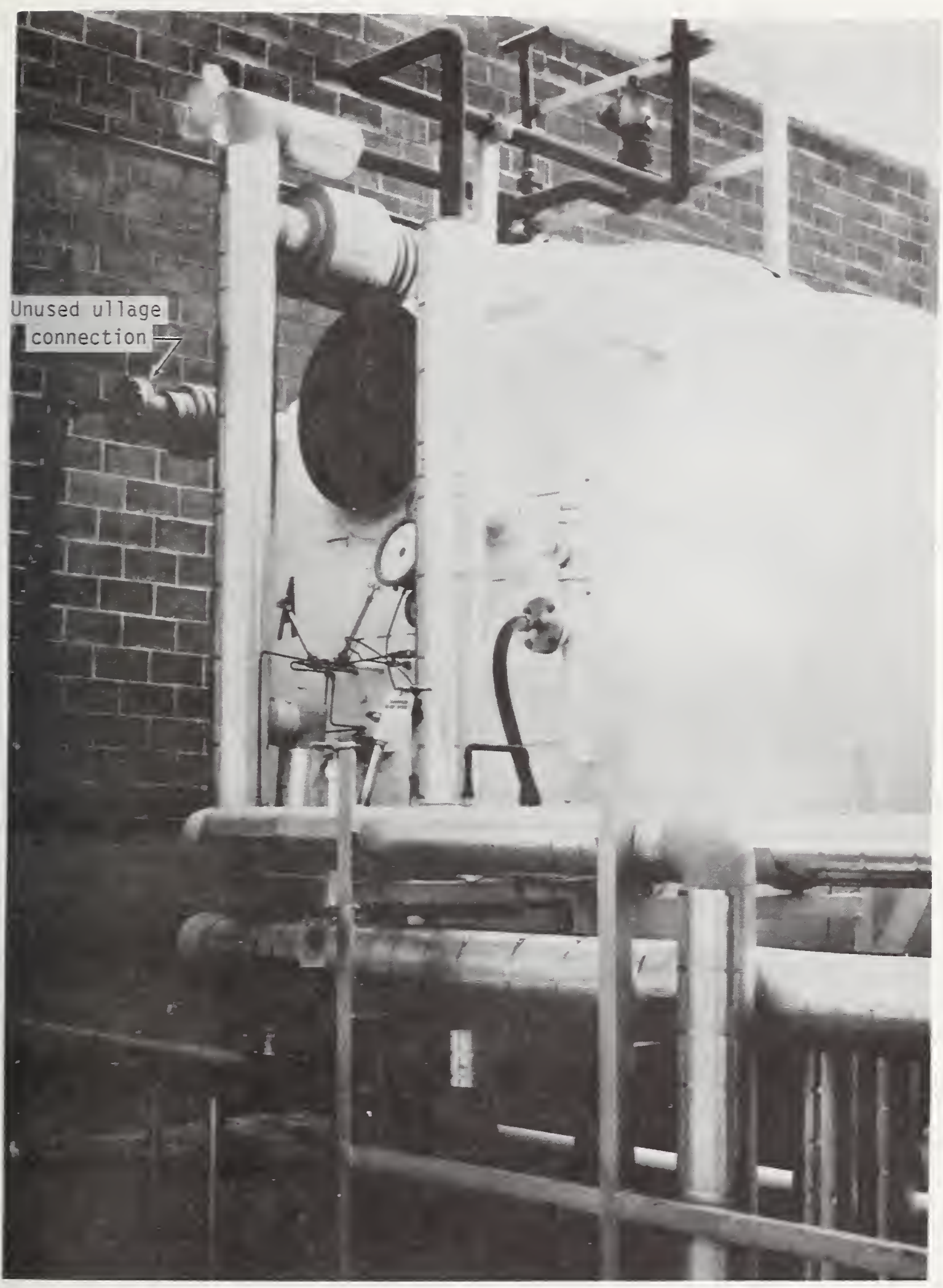

Figure 2. Storage tank A showing the unused ullage connection. 


\subsubsection{Protective clothing for use in the nitrogen storage area}

Protective clothing is suggested by most safety manuals for use when handling liquid nitrogen. The clothing includes: goggles or face shield, gauntlet leather gloves, and boots or high-top shoes covered by cuffless, clean, tightly woven white cotton coveralls. However, this type of clothing is considered to be quite conservative for the protection it provides from the cold burns resulting from large scale liquid nitrogen spills. In a system such as the wind tunnel liquid nitrogen storage area -- where the plumbing is hard and has no quick disconnects, etc. -- the chance of a line rupture is remote and the chance of a large spill where the protective clothing would serve a useful function is even more remote. Therefore, it is reasonable to relax the protective clothing requirements after some experience is gained with the storage system. The best assurance of personnel safety lies in the safety-education of the operators themselves and in a properly designed system that is in good order. We believe that the equipment meets those criteria and that the operators are responsible and knowledgeable. Therefore, the requirement that they wear all the suggested protective clothing appears to be ultra-conservative. Nonetheless, the clothing should be available and easily accessible for use in emergencies.

\subsection{Tunnel structure}

The tunnel shell is 6061-T6 aluminum and the support structure that may be cooled is 347 stainless steel; both suitable for low temperature service. Warm support members are A-36 carbon steel. Thermal contraction allowance is provided by elongated mounting holes and teflon slide pads. The tunnel structure seems suitably designed and we make no recommendations for change.

\subsection{Tunnel Insulation}

We were told that the tunnel insulation (urethane foam with fiberglass epoxy vapor barrier) is sufficient to keep the outside of the insulation warm and dry during operation. However, flange areas and penetrations may get cold enough to condense air.

The liquid condensed from air on a liquid nitrogen temperature $(77 \mathrm{~K})$ surface contains 50 mol percent oxygen. Further, as the liquid evaporates, the oxygen concentration increases. Certain fuels become more flammable or even explosive when combined with oxygen rich liquid air. At one atmosphere pressure, air will not condense at a temperature above $81.4 \mathrm{~K}$; nitrogen vapor pressure at $81.4 \mathrm{~K}$ is about 1.6 atmospheres.

The normal tunnel operating temperature is above $81.4 \mathrm{~K}$ and therefore above the air condensation temperature with the exceptions below:

1) During cooldown if the tunnel static pressure is below 1.6 atmospheres, the structure could be below $81.4 \mathrm{~K}$.

2) If liquid nitrogen collects at the tunnel low point and is vented, the temperature in the uninsulated vent lines will be below $81.4 \mathrm{~K}$.

3) During tunnel operation, liquid nitrogen is entrained in the flow stream between the nitrogen injection point and the fan. At static pressures below 1.6 atmospheres, the tunnel wall in this section could be below $81.4 \mathrm{~K}$. Therefore, air could condense between the outer tunnel wall and the urethane insulation if the fiberglass vapor barrier is not tight. Urethane is not a liquid oxygen compatible material. 
We recommend reducing or eliminating the possibility of condensing air and concentrating oxygen by:

1) Controlling the cooldown and normal operation to keep all temperatures above $81.4 \mathrm{~K}$ insofar as possible,

2) Installing temperature sensors on the outside tunnel wall beneath the insulation, particularly between the liquid nitrogen injection nozzles and the fan,

3) Sampling the oxygen concentration beneath the insulation, particularly during warm up,

4) Maintaining the vapor barrier to exclude as much air as possible,

5) Installing drip trays in all areas where liquid air is known to collect, and by arranging them to evaporate the liquid quickly and prevent accumulation,

6) Installing a liquid sensor in the low point of the tunnel to prevent liquid nitrogen accumulation. See section 2.6 .2 for a suggested sensor,

7) Keeping the areas that liquid air may contact free of grease or fuels. Figure 3 shows material collected under the tunnel during a maintenance period. We were assured the area is clean during experiments, and by

8) Purging the tunnel insulation space with nitrogen at slightly above atmospheric pressure to exclude air.

\subsection{Tunnel Vent Piping and Pressure Relief}

Nitrogen is vented from the tunnel through three control valves. Fog, produced by the cold gas, tends to settle to the ground. Ejectors, figure 4, installed on the stainless steel vent stacks have eliminated that problem. However, liquid which is occasionally vented during cooldown, may strike the ground. Tunnel overpressure protection is provided by an appropriate relief valve and a rupture disk.

\subsubsection{Cryogenic valve stem position}

Two of the three vent control valves are mounted with the stems pointing down at an angle, figure 5, the third is horizontal. These valves depend on near vertical installation to keep the stem seal warm and functional. Occasionally the non-vertical valve stems freeze and the tunnel pressure control is lost. In this event the alternatives are to warmup the tunnel or to have an operator enter the room to free the valves. The latter option has been chosen on occasion as evidenced by the hammer indentations on the valve packing area in figure 6.

We recommend mounting all cryogenic valves with the stems at least $45^{\circ}$ above horizontal.

\subsubsection{Carbon liquid sensor}

A liquid sensor in the tunnel low point would assist in preventing significant liquid nitrogen accumulation. A simple sensor, unaffected by temperature, can be made using an $1 / 8$ watt carbon resistor $\left(R_{T}\right)$ in the circuit shown in figure 7. Carbon resistance is inversely proportlonal to temperature. The small current passing through the resistor heats the element above the temperature of the surroundings. Given liquid and vapor at the same temperature, the element will be warmer in gas than liquid because of the different 


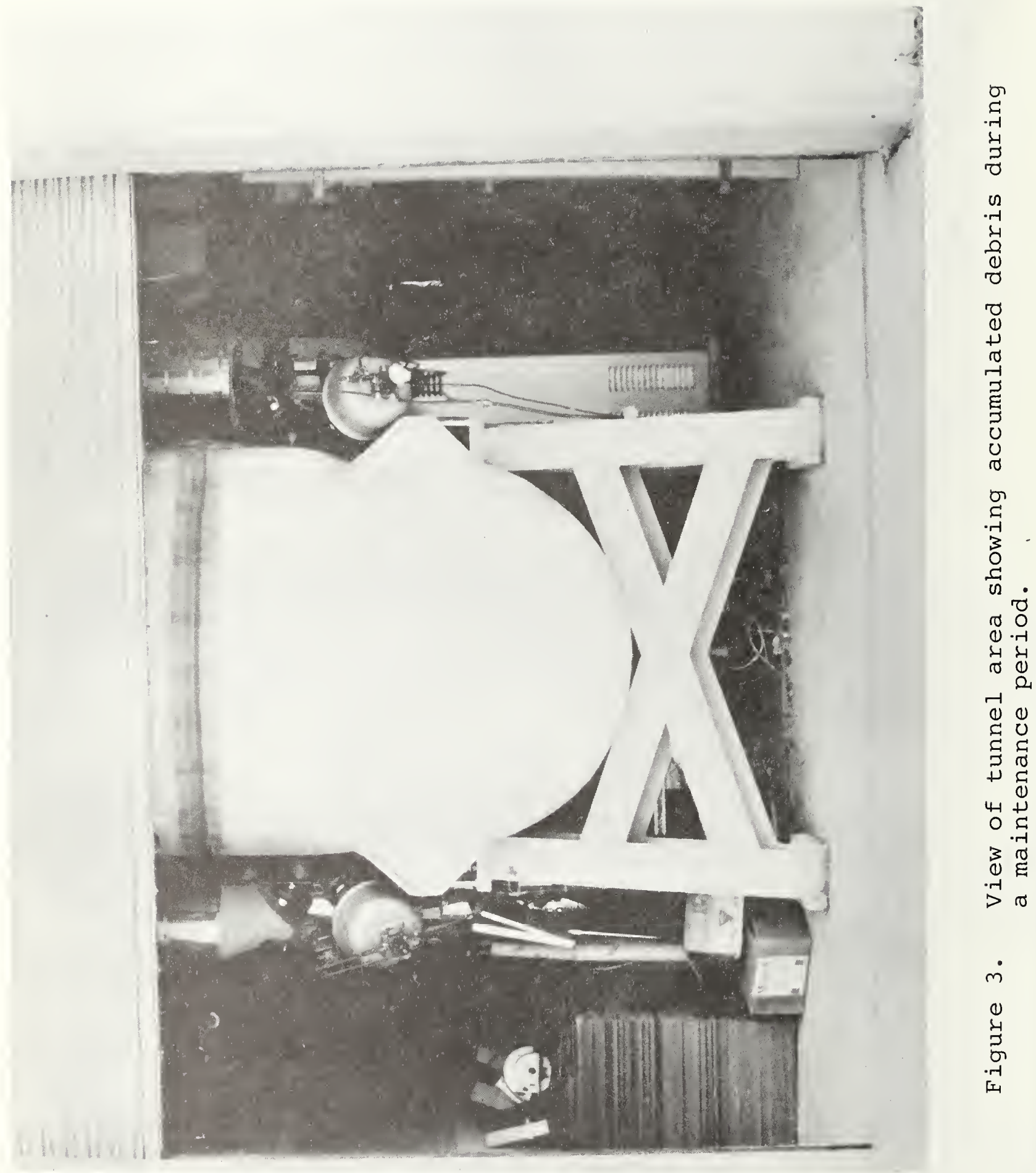




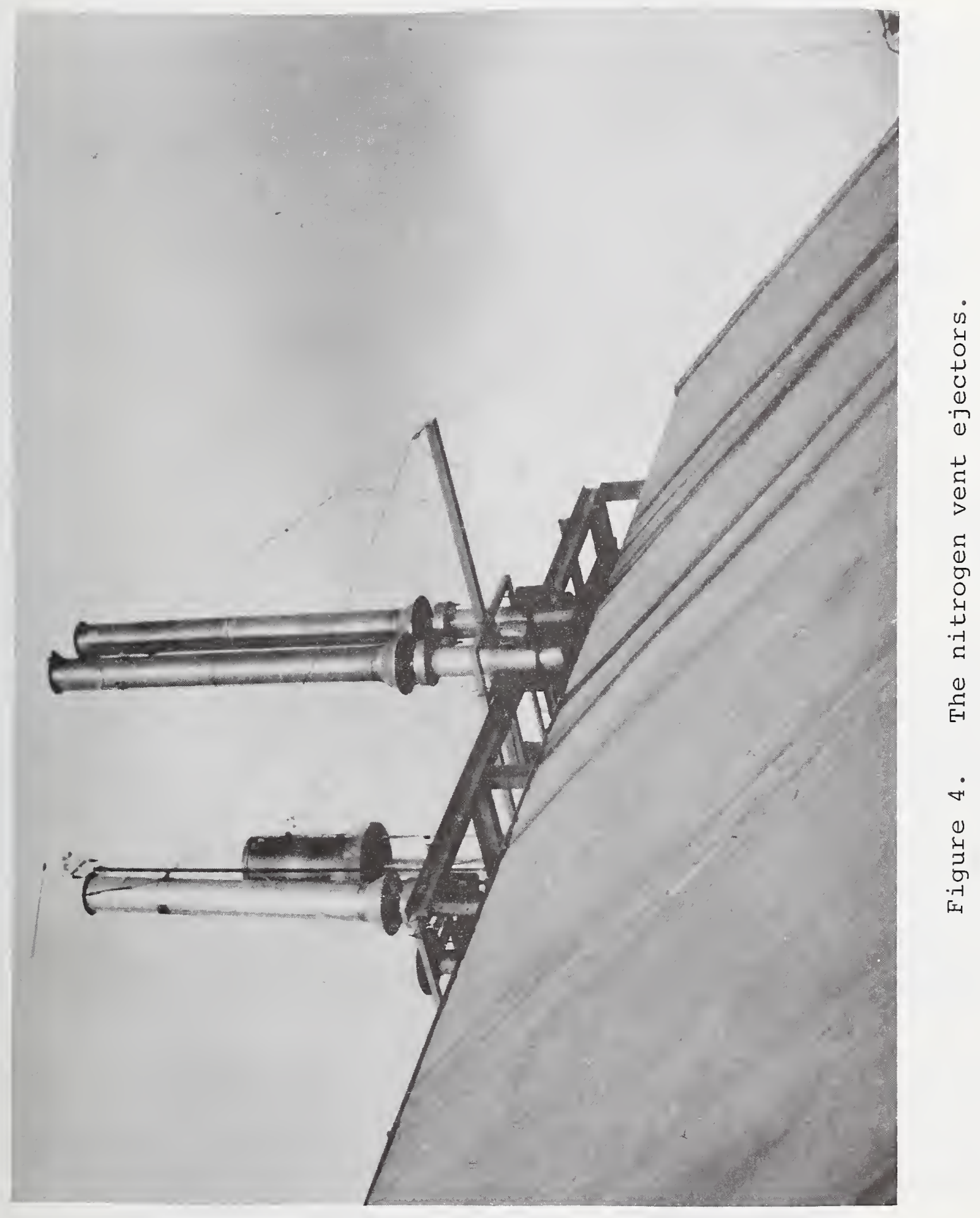




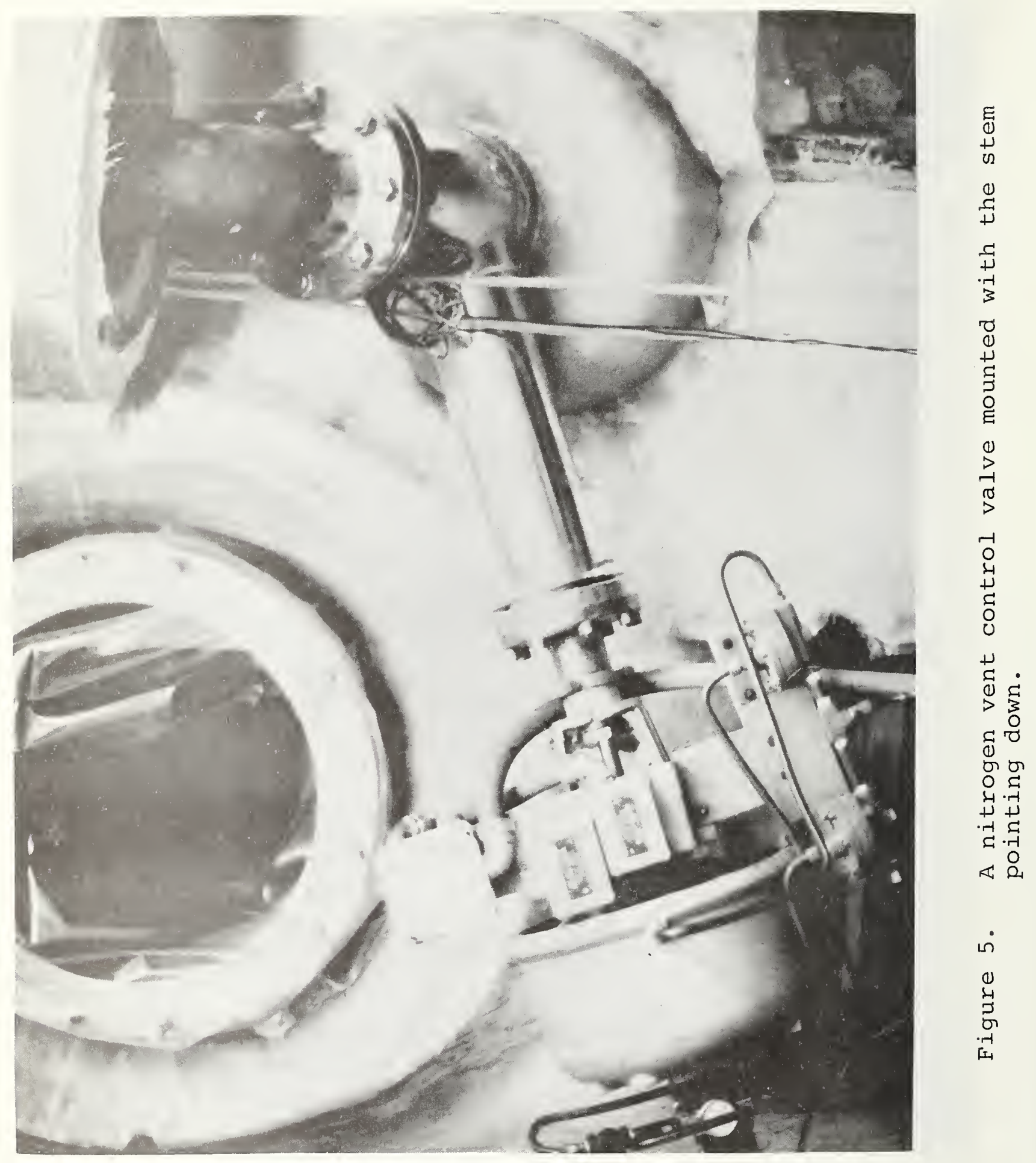




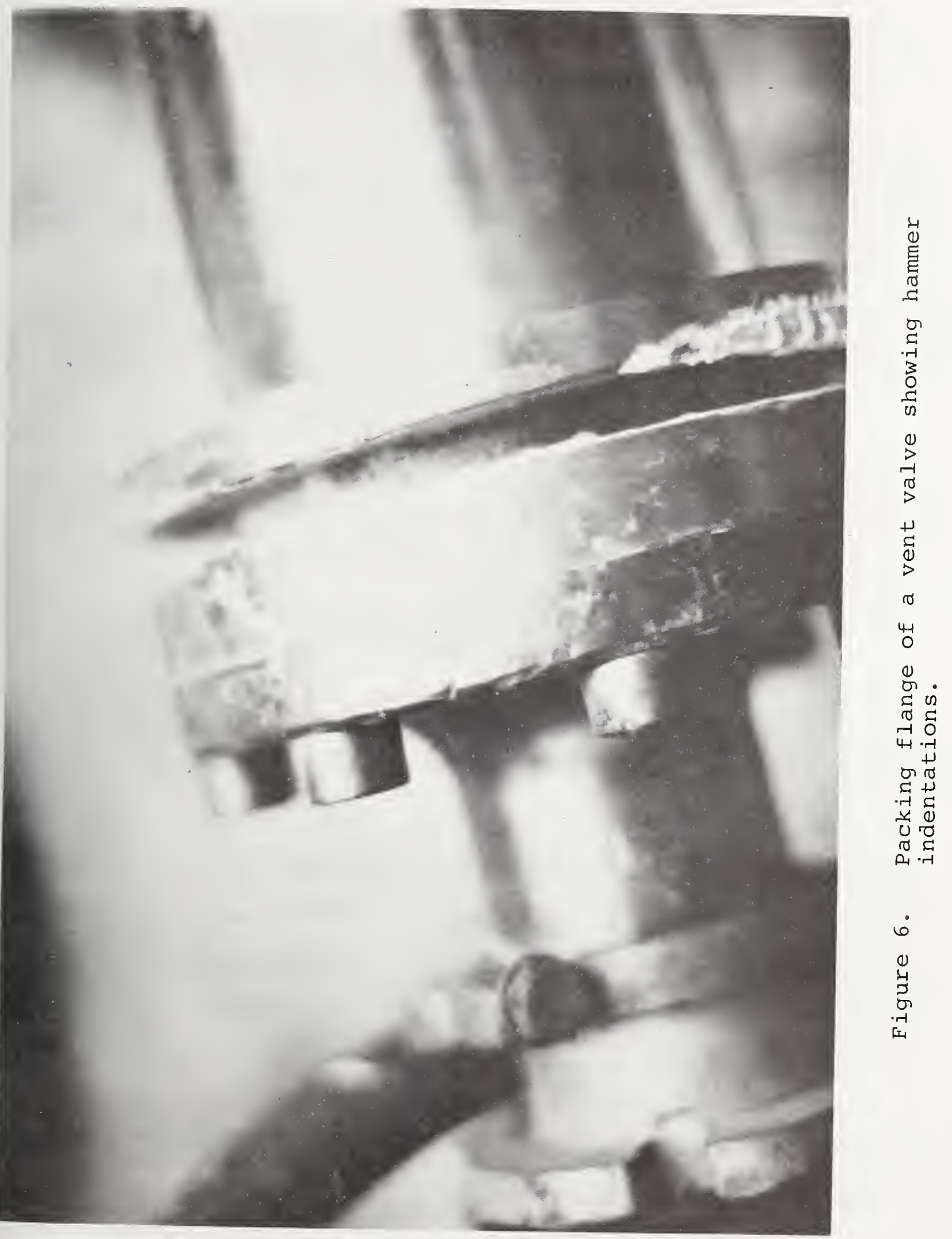




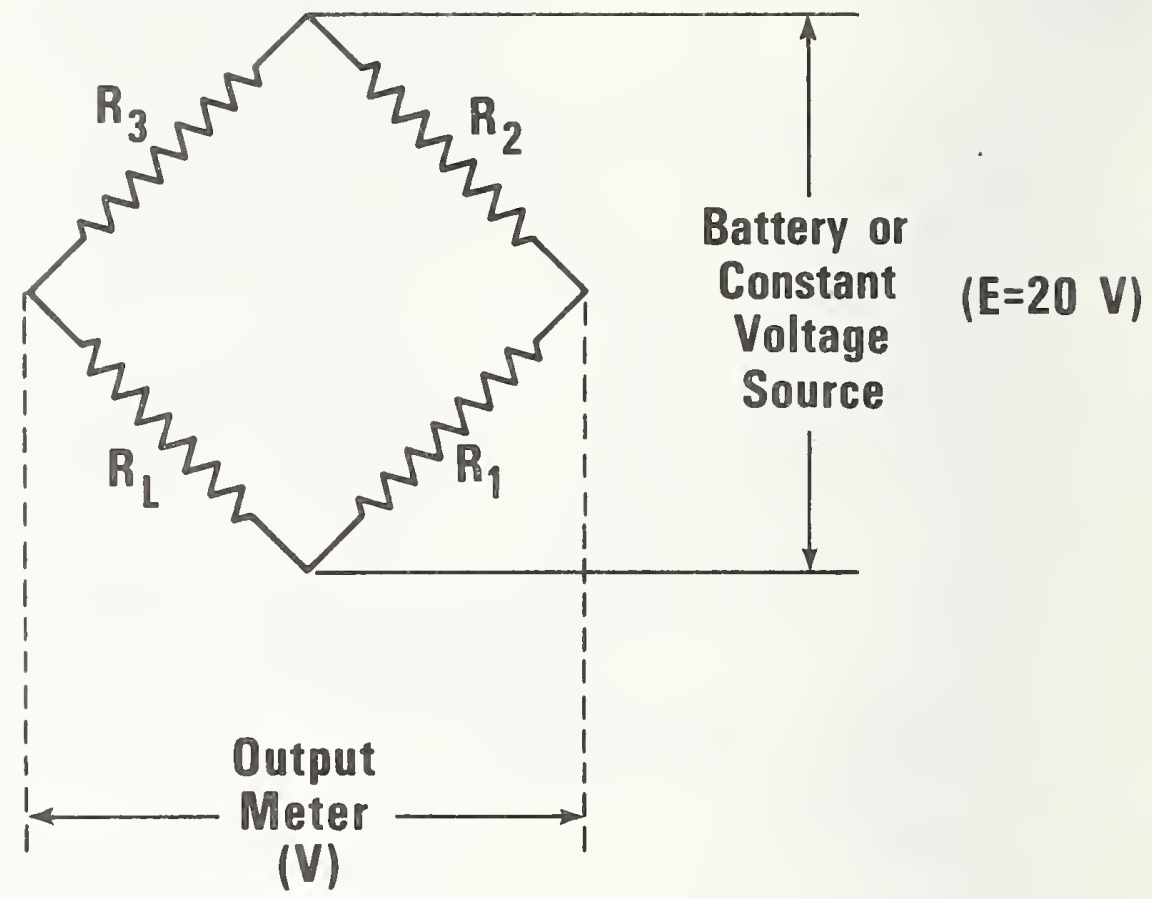

At ambient temperature $R_{1}=R_{2}=R_{3}=R_{L}=1000 \Omega$

$$
R_{1}=R_{2}=R_{3}=1 / 4 \text { watt resistor }
$$

$R_{L}=1 / 8$ watt resistor liquid sensor

output voltage(V) condition of $R_{L}$ resistance of $R_{L}$

$\begin{array}{rll}0 \mathrm{~V} & \text { Ambient Temp } & 1000 \mathrm{ohms} \\ .22 \mathrm{~V} & \text { Sat LN Vapor } & 1045 \mathrm{ohms} \\ .30 \mathrm{~V} & \text { Sat LN Liquid } & 1062 \mathrm{ohms}\end{array}$

Figure 7. Schematic of liquid level detector. 
natural convection heat transfer coefficients. The resulting change in resistance is easily detected as a step change in the bridge voltage.

Since the sensor depends on a different heat transfer coefficient in the two phases, it must be located where the flow velocities are quite low. The mounting must also minimize heat transfer from the attachment point.

\subsection{Controls and Instrumentation}

The liquid nitrogen controls and instrumentation that are not directly associated with the control of pressure and temperature in the wind tunnel are simple and adequate in their functions. Liquid level and pressure indicators for the storage tanks, manually operated vent and liquid supply valves, and a pump on-off switch constitute the liquid nitrogen control system.

We understand that the control system for the tunnel pressure and temperature is not operational except, perhaps, over a very narrow band of operating conditions. However, a new digital controller and digital valves were being installed to regulate the tunnel liquid nitrogen supply and installation of a digital controller and valves for the pressure controlling vent valves are planned in the near future to improve the control capabilities.

\subsubsection{Remote storage tank liquid level and pressure gauges}

We suggest that remote indicator gauges for liquid level and storage tank pressure be installed in the control room. Although this installation would not increase safety or utility, the remote gauges would reduce the required operator attention to gauges that are now located.outside the control room. Remote gauges for liquid level and storage tank pressure could also be installed at the liquid nitrogen fill station. These together with remotely controlled liquid fill and vent valves would allow liquid nitrogen delivery without the truck driver entering the fenced area. Appropriate locks could be used to insure that only the truck driver had access to the remote switches.

\subsubsection{House air supply - receiver}

We suggest that a receiver and appropriate check valve be installed on the house air supply to insure an air supply sufficient to at least shutdown the tunnel in the event of a air supply failure. The failure mode of the new digital valves should be incorporated into the design of the receiver system. The vent valves should fail open while the liquid nitrogen supply valves should fail closed. Instrumentation failure should be alarmed.

\subsubsection{Digital valves}

We are skeptical about the successful operation of the digital control valves being installed in the system. However, we do recognize that the cycling tests being conducted while we were making the inspection should indicate the acceptability of the valves if the tests are conducted properly. For instance, the valves should be tested in the same orientation as they will be installed and the valves should be tested at variable cycle rates. Leaving the valves open or closed for extended periods of time while they are cold would show any possibility of their freezing in position.

\subsubsection{Control system for tunnel pressure and temperature}

We also suggest that a study be conducted of the time constants associated with the tunnel pressure and temperature control system. A good control 
system will achieve the desired operating conditions in less time reducing the consumption of liquid nitrogen while reducing the required operator attention. The digital control valves currently being installed may help but our intuitive feeling is that the time constant of the tunnel is very long thus special long time constant reset and proportional controllers may be required to achieve stable control. If this is the case, the current control valves are sufficiently sensitive to achieve acceptable control and only the valve controllers need to be altered.

\subsection{Safety Systems \\ 2.8.1. Oxygen analysis}

The nitrogen in the tunnel at five atmospheres and $100 \mathrm{~K}$ would occupy 17 times the tunnel volume at standard temperature and pressure. If the tunnel ruptured, the nitrogen would displace the room air and could reduce the oxygen concentration to seriously low levels. The room is equipped with louvered vents and fans. An oxygen analyzer, sampling the room air activates an alarm system in the building and at the local fire station when the oxygen concentration is below 19 percent. The analyzer is calibrated weekly.

Normal shutdown procedure is to warm the tunnel and circulate fresh air. The tunnel fluid is analyzed to assure an adequate oxygen level prior to shutdown.

Both the systems and procedures appear to be sufficient to prevent asphyxiation.

\subsubsection{Fire control equipment}

Fires in the wind tunnel area would be Class A fires -- fires in ordinary combustible materials such as wood, paper and rubbish. The worst conditions would be a fire in the tunnel insulation with oxygen enriched air in the foam. The best fire extinguishing agent for oxygen enriched fires is water or waterfog spray which extinguishes the fire by cooling and eliminating other oxygen from the fire by the steam formed [1]. The water could be applied by automatic or remotely controlled sprinkler heads which would not require operators to enter the room and be exposed to noxious fumes from the burning insulation or asphyxiation from lack of oxygen. Although water is the most effective for large fires, other more portable $\mathrm{CO}_{2}$ or dry chemical extinguishers should be available for smaller fires.

\subsection{Physical Plant Site}

The $0.3 \mathrm{~m}$ Transonic Cryogenic Tunnel is completely enclosed by walls or fencing and is inside NASA-Langley property. The probability of intrusion and damage to the low temperature equipment is low. The storage tanks are separated from the adjacent street by a wall taller than the tanks which would deflect liquid sprayed from most plausible ruptures. Possibly a ruptured liquid line could spray into the street but the probability is low. sidered.

Even though unlikely, the consequences of a major spill should be con-

We recommend that:

1) The plot and surrounding drainage should be studied to determine if any unacceptable damage would be caused by a major spill. Dikes could be considered.

2) The effects of cold shocking the utilities (if any) in the covered trench, figure 8 , between the storage tanks should be studied. 


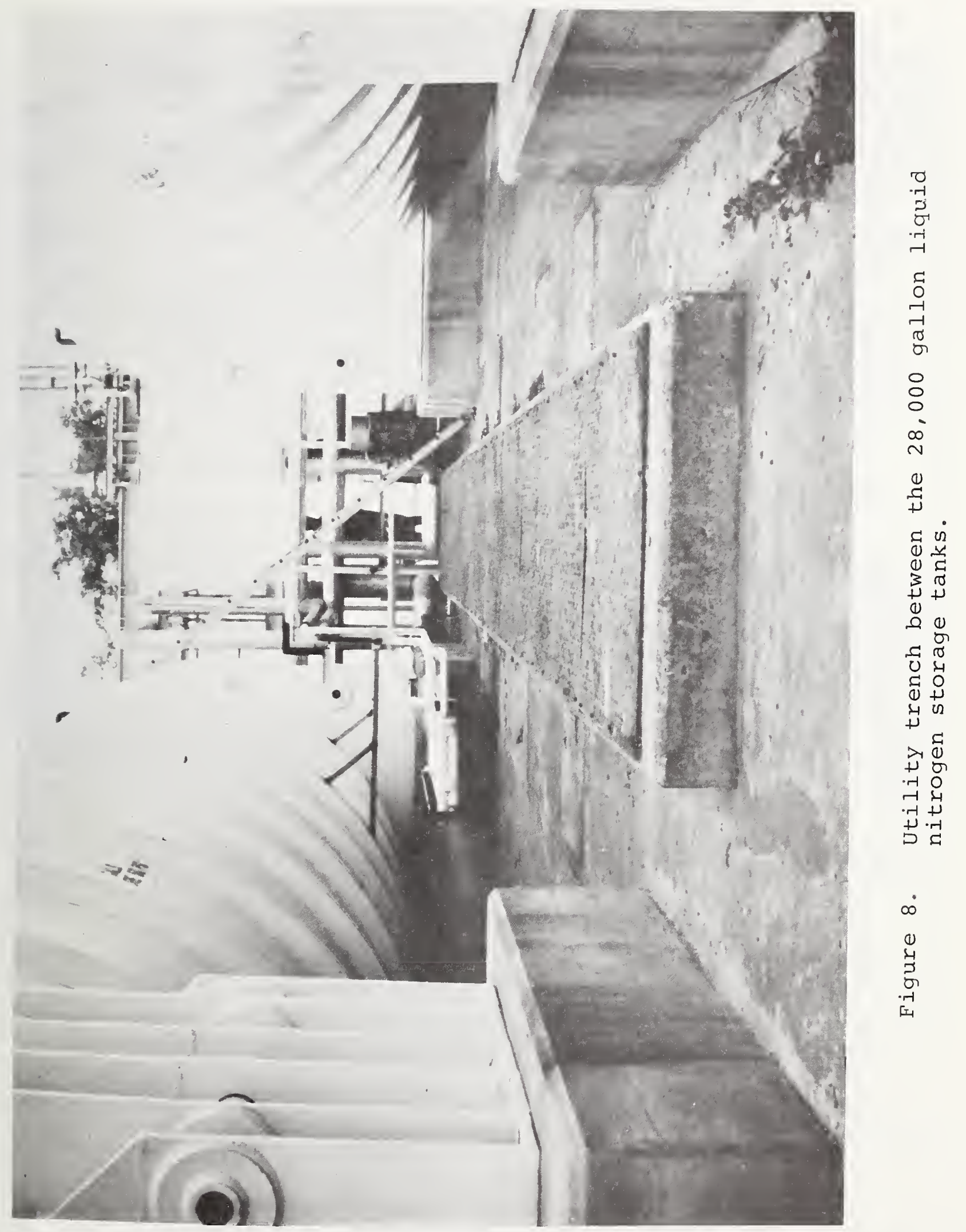




\subsection{SUMMARY OF RECOMMENDATIONS AND SUGGESTIONS}

The recommended and suggested changes to the tunnel elements made in the preceding sections can be separated into four categories: 1) Those effecting the safety of operating personnel, 2) Those preventing or reducing the possibility of equipment damage, 3) Those increasing tunnel operating ease and decreasing operator attention, and 4) Those decreasing tunnel operating costs. The categories are arranged in order of their importance; number 1 is the most important and number 4 least important. Some recommendations fit in several categories but we have placed them where we feel they have the most impact.

\section{Category 1. Operator Protection:}

1. Make protective clothing available for emergencies.

2. Install liquid air drip and evaporation trays, if necessary, based on observations of the tunnel operation by NASA-Langley personnel.

3. Keep tunnel area free of hydrocarbons or other fuels while operating.

4. Keep insulation barrier in good repair.

5. Operate tunnel walls above $81.4 \mathrm{~K}$.

6. Install temperature sensors on tunnel walls.

7. Sample oxygen concentrations in insulation space adjacent to tunnel walls.

8. Purge tunnel insulation with nitrogen.

Since oxygen accumulation in the tunnel insulation can have serious consequences, recommendations 5 through 8 are redundant. For instance, if all the tunnel wall is above $81.4 \mathrm{~K}$, no air is condensed and recommendations 7 and 8 are unnecessary. Likewise, if the tunnel insulation is completely purged with gaseous nitrogen, no oxygen will accumulate so recommendations 5, 6, and 7 are unnecessary. However, because of the possible serious consequences resulting from the condensation of air and the difficulty of assuring the absolute success of any single recommendation, we recommend the redundant approach. Since all recommendations in this category concern operator safety, we strongly recommend that all points in this category except perhaps number 5 be implemented. Implementing number 5 limits the tunnel static operating pressure to more than 1.6 atmospheres, however, if numbers 6,7 , and 8 are implemented, operating the tunnel at lower temperatures and pressures is acceptable.

Category 2. Equipment Protection:

1. Calculate fill transfer line stresses.

2. Install storage tank vacuum relief valves.

3. Redirect storage tank relief valve discharge.

4. Install and alarm an instrument air receiver and check valve.

5. Prepare storage tank and piping schematics.

6. Study site drainage and possible damage to underground utilities or other property.

Of all the recommendations in Category 2, we strongly recommend implementing number 2 . 


\section{Category 3. Operating Ease:}

1. Replumb return liquid line.

2. Install liquid sensor in tunnel low point or where liquid may collect.

3. Install tunnel vent control valves with stems vertical.

4. Install remote storage tank liquid level and pressure gauges.

We recommend numbers 1,2 and 4 in this category as low cost ways to reduce operator attention during tunnel operation. If a major overhaul of the tunnel is undertaken, we also recommend implementing number 3 .

\section{Category 4. Economics:}

1. Repair vacuum leak, Tank A.

2. Study tunnel control system.

The vacuum leak in Tank $A$ is costly in terms of $\mathrm{LN}_{2}$ consumption and we believe the repair will be less costly in the long term ${ }^{2}-$ especially if the leak is in the outer tank. We, therefore, recommend number 1 . We also recommend a further study of the tunnel control systems -- number 2 -- to reduce the cost of tunnel operation.

\subsection{REFERENCES}

1. Best's Safety Directory, A. M. Best Company, Oldwick, New Jersey, 1976, pp. 742-744.

2. Scott, R. B., Cryogenic Engineering, Book, D. Von Nostrand Company, Inc. New York, NY, 1959, pp. 221-223.

3. Moeller, C. E, J. B. Loser, W. E. Snyder, and V. Hopkins, Thermophysical properties of thermal insulating materials, Technical Documentary Report No. ASD-TDR-62-215, July 1962 . 


\section{APPENDIX A. COST OF BOILOFF LIQUID NITROGEN AS A FUNCTION OF INSULATION SPACE PRESSURE}

The daily liquid nitrogen boiloff for tank $A$ can be determined quite simply if we assume that the heat leak to the tank is proportional to the thermal conductivity of the insulation. This assumption is not entirely accurate since the heat conducted through the inner tank supports, and connecting piping does not change with insulation space pressure. Typically, the insulation heat leak is 85 to 95 percent of the total tank heat leak so using the thermal conductivity of the insulation to calculate the loss of liquid gives acceptable results.

According to scott [2], a storage container of this size should have a loss rate of 0.085 percent of its total capacity per day when used with liquid oxygen or about 0.1 percent per day when used with liquid nitrogen. If we assume that liquid nitrogen costs $\$ 0.22 /$ gallon and that the thermal conductivity of evacuated perlite insulation varies with pressure as given by [3], the total cost of the boiloff liquid nitrogen can be calculated as shown in Table Al.

Table Al. Boiloff liquid nitrogen costs as a function of pressure for storage tanks A \&. B

\section{Vacuum Space Pressure}

atm. $\quad \mathrm{mmHg}$

$\begin{array}{llc}1.3 \times 10^{-1} & 100 \\ 1.3 \times 10^{-2} & 10 \\ 1.3 \times 10^{-3} & 1 \\ 1.3 \times 10^{-4} & 0.1 \\ 1.3 \times 10^{-5} & 0.01\end{array}$

Thermal Conductivity of Perlite Insulation Watt $/ \mathrm{cm} \mathrm{K}$
$3.46 \times 10^{-4}$
$2.59 \times 10^{-4}$
$1.38 \times 10^{-4}$
$3.46 \times 10^{-5}$
$1.73 \times 10^{-5}$

$$
\begin{aligned}
& \text { Liquid } \\
& \text { Lost }
\end{aligned}
$$

Gallons/day

$\begin{array}{rr}560 & 123.20 \\ 419 & 92.18 \\ 223 & 49.06 \\ 56 & 12.32 \\ 28 & 6.16\end{array}$

Cost

\$/day

23.20

2.18

2.32

6.16 


\section{INTRODUCTION}

The cost of liquid nitrogen used in the $0.3 \mathrm{~m}$ Transonic Cryogenic Wind Tunnel is sufficiently large to consider recovering the nitrogen vent gas. The two losses incurred by venting are the work expended to separate the nitrogen from air and the wasted refrigeration potentially available in the cold vent gas. The relative magnitude of the losses may be estimated from the ideal work of separation and the thermodynamic availability of the vent gas at $100 \mathrm{~K}$ (the assumed vent temperature). These works are $58 \mathrm{~J} / \mathrm{g}$ and $136 \mathrm{~J} / \mathrm{g}$, respectively, and the ideal work required to liquefy nitrogen is $769 \mathrm{~J} / \mathrm{g}$. Thus the maximum savings that can be realized by a recovery system is 23 percent of the original work required to separate and liquefy the nitrogen. Therefore, the recovery system must have a relatively high efficiency before recovering the vent gas becomes less costly than producing the liquid using a captive air-separation plant.

We have estimated the annual cost of seven recovery systems using a number of simplifying assumptions*. Even though the estimates must be refined, they show that since venting occurs periodically, recovering the gas and saving the refrigeration is expensive; in fact, nearly the same or more expensive than separating and liquefying the nitrogen supply directly from air. The estimated annual cost for each case relative to a captive air separation plant is shown in Table Bl.

Table Bl. Estimated annual cost relative to a captive air separation plant. Relative Annual Cost

Case 1: Purchase liquid

Case 2: Captive air separation plant

Case 3: Large nitrogen reliquefier

Case $4:$

Case 5:

Case 6:

Case 7:
Refrigerator and triple point storage

Refrigerator and slush storage

Nitrogen reliquefier and high pressure storage

Nitrogen reliquefier and low pressure storage
2.3

Base line

1.8

1.6

1.5

1.5

2.1

The following tunnel operating profile is assumed in the analysis:

1) liquid nitrogen flow rate

2) vent gas temperature

3) vent gas pressure

4) experiment duration

5) frequency of experiments

6) time elapsed between experiment starts

7) number of weeks experiments conducted
150 gallon/minute

$100 \mathrm{~K}$

$1.0 \mathrm{~atm}$

5 hour/day

$4 /$ week

24 hours

52 /year

We assumed a high nitrogen use rate (corresponding to maximum tunnel test Reynolds numbers) so the recovery system costs are the lowest per unit of nitrogen used. The actual tunnel operating profile uses nitrogen at $1 / 4$ to 1/8 the assumed rate. A recovery system not attractive at the assumed high use rate will be even less attractive at the actual lower nitrogen use rates. 


\section{SYSTEM DESCRIPTIONS AND REMARKS}

Case 1: Purchase liquid.

Purchase the required liquid at $\$ 0.22 /$ gallon.

Case 2: Captive air separation plant.

Purchase and continuously operate, an air separation-nitrogen liquefier dedicated to the $0.3 \mathrm{~m}$ Tunnel.

Case 3: Large nitrogen reliquefier.

Purchase a nitrogen reliquefier large enough to reliquefy the nitrogen as it is vented. The reliquefier would be large and impractical to start and stop for each experiment.

Case 4: Refrigerator with triple point liquid storage.

In this system, a refrigerator runs four days a week to cool stored liquid nitrogen to the triple point. At the beginning of a tunnel run, the storage vessel is 70 percent full of triple point liquid. During the run, the vent gas is bubbled into the liquid and condensed. At the end of a five hour run the vessel is nearly full of normal boiling point liquid. Liquid is then drawn off to the 70 percent level as the refrigerator continues to run and the cycle is repeated. Although the refrigerator operates with a nearly continuous load, the irreversibility of mixing and condensing the $100 \mathrm{~K}$ vent gas in the 63 to $77 \mathrm{~K}$ liquid lowers the process efficiency and increases the refrigerator size. The cost incurred by the irreversibilities and the large storage tank make this system more expensive than the baseline.

Case 5: Refrigerator and slush storage.

This system is different from Case 4 in that a 50:50 mixture of triple point solid and liquid (slush) is used to condense the vent gas. The storage tank is smaller than in Case 4 because the latent heat and density of the slush are higher than for liquid. Opposing the lower storage vessel cost is a higher refrigerator cost due to the higher average temperature difference between the vent gas and the slush. No economic advantage is apparent in this system.

Case 6: Nitrogen reliquefier and high pressure storage.

In this system, the vent nitrogen is compressed into 140 atm cylinders during a tunnel run. The stored gas is continuously liquefied in preparation for the subsequent experiments. The available refrigeration is lost and the compression and storage equipment is expensive. The system is not economically attractive.

Case 7: Nitrogen reliquefier and low pressure storage.

In this, the most expensive system, a low pressure gas holder collects the vent gas which is then reliquefied. The cost of the gas holder is dominant.

\section{PERFORMANCE AND COST ESTIMATES}

The following values were used for the performance and cost of the system components and for power. 
1) Refrigerators and liquefiers

A. Efficiency

A thermodynamic efficiency of 30 percent of Carnot was assumed for all systems considered.

B. Capital Cost

Cost in dollars $=7260 \times$ (input power, $\mathrm{kw})^{0.7}$

2) Capital cost of Storage

A. Liquid and Slush Nitrogen Storage Vessels Total capital cost $=\$ 10 /$ gallon

B. High Pressure Storage Cylinders

$\$ 24 /$ kilogram of stored ambient temperature nitrogen or $\$ 11 / 1 b$ of stored ambient temperature nitrogen

c. Low Pressure Gas Holder

$\$ 600 /$ kilogram of stored ambient temperature nitrogen or $\$ 272 / 1 b$ of stored ambient temperature nitrogen.

3) Power Cost

$$
\$ .025 / \mathrm{kW}-\mathrm{h}
$$

4) Compressor for High Pressure Storage

\author{
A. Capital cost \\ Compressor - $\$ 350 / \mathrm{kW}$ input power \\ Electric Drive - $\$ 54 / \mathrm{kW}$ input power
}

5) Annual cost

The annual costs are 18 percent of the total capital costs for the liquefiers, refrigerators and storage containers. About 15 percent is the annual cost of the capital and the remaining 3 percent is operating and maintenance expense.

Table B2 shows a summary of the total annual costs of recovering the venting nitrogen from the $0.3 \mathrm{~m}$ Transonic Cryogenic Wind Tunnel. The lowest cost system is Case 2 -- a captive air separation plant. Even though 23 percent of the original work required to separate and liquefy the nitrogen is still available in the vent gas; the periodic nature of the tunnel operation results in a high recovery cost. Our assumption of operating the tunnel 52 weeks a year is conservative because reduced operation will decrease only the power costs of Cases 2 through 7 while the annual capital costs remain constant. If the tunnel operates less than 12 weeks a year then purchasing the liquid nitrogen at $\$ 0.22 /$ gallon becomes the least costly (Case 1 ).

We assumed a temperature of $100 \mathrm{~K}$ for the venting nitrogen, but the tunnel will also operate at higher temperatures resulting in even higher recovery costs. Although the recovery systems are not currently competitive in cost with a captive air separation and nitrogen liquefaction facility, a higher electrical power cost would change this comparison. The electrical power cost needs to rise to a value six times its current cost $(\$ .025 / \mathrm{kW}-\mathrm{h})$, however, before Case 4 would be competitive with the captive air separation plant. 


\section{RECOMMENDATIONS}

Recognizing that the maximum recovery system saving is 23 percent of the original energy required to separate and liquefy the nitrogen and that recovery system irreversibilities are inevitable, we nonetheless feel that further study of recovery systems is prudent and may be fruitful. Certainly concepts other than those in this report should be examined with regard to cost and engineering practicality. One of the first tasks should be to refine the costs given in this report which are estimates not based on manufacturer contact for the specific items. 
Table B2. Summary of estimated costs to recover the nitrogen vent gas from the $0.3 \mathrm{~m}$ Transonic Cryogenic Tunnel

CASE 1: PURCHASE LIQUID

$9.36 \times 10^{6}$ gallons/year @ $\$ 0.22 /$ gallon

Total annual cost $\$ 2,059,000.00$

CASE 2: CAPTIVE AIR SEPARATION PLANT

Air Separation Plant
Capital Cost - $\$ 1.936 \times 10^{6}$
Power Cost

Annual cost

$348,500.00$

$547,000.00$

Storage container

(Use existing storage)

Total annual cost

$\$ \overline{895,500.00}$

CASE 3: LARGE NITROGEN RELIQUEFIER

Reliquefier
Capital Cost - $\$ 6.4 \times 10^{6}$
Power Cost

Total annual cost

Annual cost

$1,152,000.00$

$\frac{418,000 \cdot 00}{\$ 1,570,000.00}$

CASE 4: REFRIGERATOR AND TRIPLE POINT STORAGE
A. Refrigerator
Capital Cost -- $\$ 2.19 \times 10^{6}$
Power cost
Annual cost
$394,200.00$
$434,200.00$
B. Storage Container
356,813 gallons
cost $\$ 3.57 \times 10^{6}$
Total annual cost $\quad \$ 1, \frac{642,600.00}{471,000.00}$

CASE 5: REFRIGERATOR AND SLUSH STORAGE

A. Refrigerator

Capital Cost - $\$ 2.26 \times 10^{6}$
Power Cost

Annual cost

$406,800.00$

$454,200.00$

B. Storage container

273,690 gallons

costs $\$ 2.74 \times 10^{6}$

Total annual cost

$\$ 1, \frac{493,200.00}{354,200.00}$

CASE 6: NITROGEN RELIQUEFIER AND HIGH PRESSURE STORAGE

Reliquefier

Capital cost -- $1.8 \times 10^{6}$

Power

Annual cost

$324,000.00$

$508,600.00$

Compressor to fill high pressure storage

Capital cost -- $2.29 \times 10^{6}$

Power

$412,200.00$

$72,800.00$

High Pressure Storage Cylinders 6

Capital cost - .056 × $10^{6}$

Total annual cost

$\$ 1, \frac{10,100.00}{327,700.00}$ 
Table B2. Summary of estimated costs to recover the nitrogen vent gas from the $0.3 \mathrm{~m}$ Transonic Cryogenic Tunnel (continued)

CASE 7: NITROGEN RELIQUEFIER AND LOW PRESSURE STORAGE

Reliquefier

Capital Cost - $\$ 1.8 \times 10^{6}$

Power Cost

Annual cost

$324,000.00$

$508,600.00$

Low Pressure Gas Holder

Capital Cost - $\$ 5.94 \times 10^{6}$

Total annual cost

$\frac{1,069,200.00}{\$ 1,901,800.00}$ 


\begin{tabular}{|c|c|c|}
\hline $\begin{array}{l}\text { 1. PUBLICATION OR REPORT NO. } \\
\text { NBSIR } 77-857\end{array}$ & $\begin{array}{l}\text { 2. Gov't Accession } \\
\text { No. }\end{array}$ & 3. Recipient's Accession No. \\
\hline \multicolumn{2}{|l|}{ 4. TITLE AND SUBTITLE } & 5. Publication Date \\
\hline \multirow{2}{*}{\multicolumn{2}{|c|}{$\begin{array}{l}\text { CRYOGENIC DESIGN AND SAFETY REVIEW NASA-LANGLEY } \\
\text { RESEARCH CENTER } 0.3 \text { METER TRANSONIC CRYOGENIC } \\
\text { TUNNEI }\end{array}$}} & Apri1 1977 \\
\hline & & $\begin{array}{l}\text { 6. Performing Organization Code } \\
275.05\end{array}$ \\
\hline \multicolumn{2}{|l|}{$\begin{array}{l}\text { 7. AUTHOR(S) } \\
\text { R. O. Voth and T. R. Strobridge }\end{array}$} & 8. Performing Organ. Report No. \\
\hline \multirow{2}{*}{\multicolumn{2}{|c|}{$\begin{array}{l}\text { 9. PERFORMING ORGANIZATION NAME AND ADDRESS } \\
\text { NATIONAL BUREAU OF STANDARDS } \\
\text { DEPARTMENT OF COMMERCE } \\
\text { WASHINGTON, D.C. } 20234\end{array}$}} & $\begin{array}{l}\text { 10. Project/Task/Work Unit No. } \\
2750558\end{array}$ \\
\hline & & 11. Contract/Grant No. \\
\hline \multirow{2}{*}{\multicolumn{2}{|c|}{$\begin{array}{l}\text { 12. Sponsoring Organization Name and Complete Address (Street, City, State, ZIP) } \\
\text { National Aeronautics and Space Admin. } \\
\text { Langley Research Center } \\
\text { Hampton, VA } 23365\end{array}$}} & $\begin{array}{l}\text { 13. Type of Report \& Period } \\
\text { Covered }\end{array}$ \\
\hline & & 14. Sponsoring Agency Code \\
\hline
\end{tabular}

15. SUPPLEMENTARY NOTES

16. ABSTRACT (A 200-word or less factual summary of most significant information. If document includes a significant bibliography or literature survey, mention it here.)

The findings of a Cryogenic Design and Safety Review of the NASA-Langley $0.3 \mathrm{~m}$ Transonic Cryogenic Tunnel are presented in this report. The tunnel working fluid and coolant is nitrogen. The nitrogen, supplied as liquid, is exhausted as a low temperature gas. The use and storage of liquid nitrogen at the facility presents several potential hazards to personnel and equipment. An appropriate cryogenic design minimizes these risks, and provides for convenient tunnel operation and for the economical use of the liquid nitrogen. The tunnel and ancilliary systems are generally well designed but several recommendations to improve the cryogenic systems are made. The cost of recovering the cold vent gas is compared to the cost of producing the required liquid nitrogen using a captive air separation plant. Although the economic analysis is preliminary, it shows that because of the periodic operation of the tunnel, a captive air separation plant has a lower annual operating cost than the vent gas recovery systems considered.

17. KEY WORDS (six to twelve entries; alphabetical order; capitalize only the first letter of the first key word unless a proper name; separated by semicolons)

Cryogenic; design; nitrogen; safety; wind-tunnel.

XX Unlimited

For Official Distribution. Do Not Release to NTIS

Order From Sup. of Doc., U.S. Government Printing Office Washington, D.C. 20402, SD Cat. No. C13

XX Order From National Technical Information Service (NTIS) Springfield, Virginia 22151

\begin{tabular}{|l|c|}
\hline $\begin{array}{l}\text { 19. SECURITY CLASS } \\
\text { (THIS REPURT) }\end{array}$ & 21. NO. OF PAGES \\
UNCL ASSIFIED & 27 \\
\hline $\begin{array}{l}\text { 20. } \begin{array}{c}\text { SECURITY CLASS } \\
\text { (THIS PAGE) } \\
\text { UNCLASSIFIED }\end{array} \\
\text { 22. Price }\end{array}$ & $\$ 4.00$ \\
\hline
\end{tabular}




$$
\text { . }
$$

